\title{
Family Socialization, Economic Self- Efficacy, and the Attainment of Financial Independence in Early Adulthood
}

\author{
Jennifer C. Lee* \\ Indiana University \\ Jeylan T. Mortimer \\ University of Minnesota \\ *Corresponding author. Email: lee484@indiana.edu
}

\begin{abstract}
The attainment of financial independence is a key marker of the contemporary transition to adulthood. In this study we ask, how do young adults gain the capacity to support themselves? We contend that communication about work in the family during adolescence is an important precursor of economic self-efficacy during adolescence, which is positively associated with financial independence in early adulthood. Drawing upon rich longitudinal data that span adolescence and young adulthood, we first ask whether family communication and socialization practices surrounding work and finances influence the development of ways of thinking about oneself that imply self-reliance and confidence in the economic domain (economic self-efficacy). Second, we assess whether economic self-efficacy, measured during adolescence, has a long-term influence on the transition to adulthood, status attainment, and financial independence. Our findings indicate that direct communications about work with parents foster the development of economic self-efficacy. This positive dimension of the selfconcept fosters achievement during the transition to adulthood (e.g., educational achievement, employment status, and income attainment), which, in turn, heighten financial independence in early adulthood.
\end{abstract}

\section{Keywords}

Economic socialization; attainment; family

\section{Acknowledgements}

This paper was presented at the 2005 Annual Meeting of the American Sociological Association, Philadelphia. The Youth Development Study is supported by a grant, "Work Experience and Mental Health: A Panel Study of Youth," from the National Institute of Child Health and Human Development (HD44138). It was previously supported by the National Institute of Mental Health (MH42843). The content is solely the responsibility of the authors and does not represent the official views of the National Institute of Child Health and Human Development or the National Institutes of Health. 


\section{Introduction}

The attainment of financial independence is a critical component of the contemporary transition to adulthood. Financial independence is closely linked to major demographic markers of this transition. The start of a career, usually following the completion of formal schooling, fosters economic independence, which, in turn, can provide the financial wherewithal for other markers of adulthood, such as residing outside the parental home, marriage and parenthood. In addition, difficulties in becoming financially independent can precipitate a return to the family of origin after becoming residentially independent (Goldscheider and Goldscheider, 1994); such problems may also lead to welfare dependency. Along with its linkage to these demographic markers of adulthood, financial independence has considerable psychological salience to young people themselves. When asked to consider what is necessary to become an adult (Arnett, 1994, 1998), young adults point to financial independence as a central consideration. In addition, Furstenburg et al (2004) report that among respondents to the 2002 U. S. General Social Survey, $97 \%$ said that financial independence is at least somewhat important to being considered an adult. Surprisingly, despite the importance of financial independence in the transition to adulthood, little research has been conducted on the factors that foster the attainment of this desired state.

In this paper, we contend that economic self-efficacy is a key precursor of economic independence in early adulthood. In addition, we suggest that socialization processes that occur within the family during adolescence might influence economic self-efficacy. The present research builds on a wide-ranging body of prior work in the status attainment tradition and in social psychology by examining a rich longitudinal data set for plausible familial and psychological precursors of financial independence in early adulthood. Specifically, we investigate the role of family communication and socialization, operationalized by hearing parents talk about work, parent-child discussions about work, work arrangements in the home (chores and special work projects for which the child is paid), and the receipt of a regular allowance. Drawing upon panel data that span adolescence and young adulthood, we first ask whether these socialization practices surrounding work and finances influence the development of ways of thinking about oneself that imply self-reliance and confidence in the economic domain (economic self-efficacy). Second, we assess whether economic self-efficacy has a long-term influence on the transition to adulthood and status attainment, thereby affecting financial independence in young adulthood.

\section{Background}

\section{Prior Research}

Many social science literatures have relevance to educational and occupational achievement, but do not address financial independence directly. A well-developed body of research has examined the antecedents of socioeconomic attainment, as indicated by years of schooling, educational credentials, occupational prestige, and, of greatest interest here, earned income (Sewell and Hauser, 1975; Featherman, 1980). This work highlights family socio-economic background, as well as adolescents' educational and occupational aspirations and plans, as precursors of adult attainments. There is also a long-standing tradition of research on intergenerational transfers of wealth (Kohli, 2003; Keister, 2003). The absence of wealth among minority families seriously reduces the educational prospects and earning potential of their children (Orr, 2003). However, the attainment of socioeconomic status, even income, while clearly linked to financial independence, is not the same; many young people (and adults) with seemingly good jobs and adequate earnings are plagued by overwhelming debt and financial insecurity.

Several institutional features of contemporary American society foster prolonged financial dependency, high levels of young adult indebtedness, and considerable difficulty and anxiety surrounding selfsupport. Shifts in the economic structure have made the achievement of financial independence particularly challenging for young people. Whereas youth entering the labour market after high school in the mid-twentieth century had access to good blue collar jobs that could support a family (Schneider and Stevenson, 1999), labour market opportunities for young people who do not have specialized training or college degrees have declined precipitously. Indeed, young people (age 18-32) in the U.S. are more likely to have poverty-level incomes than their counterparts in five other industrialized 
countries (Smeeding and Phillips, 2002). In addition, rapid technological change, economic turbulence, and organizational instability complicate career decision-making and diminish the likelihood of stable career progressions that yield high earnings and the receipt of health insurance and other benefits. These social and technological changes, and consequent employment restructuring, increase uncertainty and make the transition from school to work more difficult for contemporary cohorts of youth in Britain, Germany, and other post-industrial societies as well as in the United States (Bynner, 1998; Bynner and Parsons, 2002; Heinz, 2003).

These macroeconomic trends give young people strong incentives to pursue postsecondary education to enhance their credentials in an increasingly competitive labour market. The extension of higher education has marked personal benefits for youth (Pallas, 2003), but by prolonging the transition to adulthood (Shanahan, 2000) higher education also lengthens the duration of time that young people are at least partially, and often substantially, financially dependent on their parents. Fifty-three percent of U.S. students entering 4-year colleges in 1995-96 earned a bachelor's degree within five years; 17 percent were still enrolled by 2000-2001 (National Center for Educational Statistics, 2004). The growing cost of higher education, coupled with a reduction in grant programmes, have made it necessary for many young people to accrue large amounts of debt by the time they leave school. With limited financial backing from parents, many college students increasingly look beyond their families for tuition and living expenses, to federal and other loans, supplemented by their own wages from part-time jobs as they attend school (Christie, Munro and Rettig, 2002). Some move in and out of higher degree programmes as their financial circumstances permit. Those who eventually obtain the BA have typically amassed over $\$ 22,000$ in loans by the time of graduation. Many recent graduates must set aside more than $8 \%$ of their monthly incomes to pay off student loans (King and Bannon, 2002).

As a result of these and other trends, many young people find themselves in difficult financial situations well after they have completed their formal schooling. They typically turn to their parents for help. In fact, analysis of data from the Panel Study of Income Dynamics and the U.S. Census showed that the average financial contribution of parents to children aged 18-34 was $\$ 2,200$ annually (Schoeni and Ross, 2004), and many young adults receive support from their parents even when they are employed (Furstenberg et al, 2003).

Under these often trying circumstances, why do some young people move rather smoothly toward financial independence, and others remain dependent on their parents well into their twenties? How do young people gain the capacity to support themselves and how do they acquire confidence in being able to comfortably manage their finances? Given the high psychological salience of financial independence for young adults, as well as its significance for multiple aspects of adult role enactment, it is rather surprising that this phenomenon has received so little systematic scrutiny. Contemporary "economic sociology" is squarely focused on the macro level of analysis, to the neglect of micro-level experiential and social-psychological precursors of financial independence.

Rarely are experiences in the family setting examined as sources of financial independence. One exceptional study (Whittington and Peters, 1996), using longitudinal data from the Panel Study of Income Dynamics, examined the sources of independence, defined jointly by leaving the parental home and by achieving financial self-sufficiency. Parental income was found to be associated with greater dependence up to the age of 18 or 19, after which it predicted greater independence. The authors reason that "higher income parents have greater resources to induce their children to avoid ...behaviours [such as early childbearing and marriage] and to remain dependent on them." Another study by Aquilino (2005) found that family structure had an influential role in parental attitudes towards economic support of their adult children. Parents in intact families (those with both biological parents in the household) were more likely than single parents or step-parents to believe that parents should provide financial support to their children as they transition to adulthood. These studies, however, did not address family communication processes relevant to work and earnings that could foster the achievement of financial independence.

Although parents of higher socioeconomic status present role models to their children signifying economic success, such attainment in itself may be insufficient to instill a sense of economic efficacy and behaviours in children that promote their own financial independence. Parents may be more or less salient role models to their children, depending largely on the closeness of the relationship between parent and child. Consistent with Kohn's "occupational linkage hypothesis" (Kohn, 1981; Kohn and Schooler, 1983), parental work values, linked to parental occupations, are found to affect children's values only under conditions of parental support and communication that facilitate parental 
identification (Mortimer, 1976; Mortimer and Kumka, 1982; Mortimer, Lorence and Kumka, 1986; Ryu and Mortimer, 1996). Therefore, the present research focuses on the role of family socialization and communication in the development of economic self-efficacy in adolescence, which could foster adult role transitions and attainments that enable financial independence in young adulthood.

\section{Economic Self-Efficacy}

The pervasive consequences of control beliefs for persistence and success in the face of obstacles are well known (Bandura, 1997). Caplan and Schooler (2007) report that self-confidence and non-fatalistic beliefs are linked to a strategy of coping with financial difficulties that is problem-focused (rather than emotion-focused). Self-efficacy in particular is an important determinant of behaviours in many domains. Domain-specific beliefs of efficacy during adolescence may be valuable for later attainments because they promote more effective goal-oriented behaviour. Perceptions of economic self-efficacy, once formed, appear to be critical in fostering achievement-relevant behaviours. For example, youth who think they will be successful in achieving their goals, and specifically those in the economic realm, are likely to be more persistent in their preparation and striving for post-secondary education. In fact, the belief that one will be successful in the economic realm is found to enhance academic achievement (grade point average) and educational goals during high school, to increase the likelihood of behaviours conducive to college enrollment (such as seeing counsellors, requesting applications, etc.), and to promote actual post-secondary educational attendance (Grabowski et al, 2001). The higher level of educational attainment thereby promoted could foster financial independence by increasing the likelihood of full-time employment and the stability of earnings in early adulthood. It is likely that high levels of efficacy would also lead to a delay in family formation, to enable postsecondary educational achievement. Thus, youth with higher levels of economic efficacy would likely experience delayed transitions to adulthood, characterized by prolonged school attendance, higher levels of educational and income attainment, and delayed marriage and parenthood.

Bandura (1977) contends that four factors contribute to perceptions of efficacy: personal accomplishments, vicarious experience, verbal persuasion and physiological state. This formulation suggests that beliefs about one's economic self-efficacy are dependent upon the observation of, and persuasion from, others, in addition to one's own achievements and feelings. Little research, however, has examined the influence of the family on the development of this positive self-perception. Grabowski et al (2001) find that family background indirectly influences perceptions of economic self-efficacy through youths' own school and work experiences. In addition, among non-working youth, parents' income was found to be positively related to youths' beliefs about their economic futures. These findings suggest that adolescents may develop a sense of efficacy by observing their parents' achievement. Yet to be examined, however, is whether communication between family members about economic matters influences adolescents' developing sense of confidence in this sphere.

\section{Socialization and Family Communication Processes}

We suggest that family socialization, particularly communication about work and money, is an important factor in the development of economic self-efficacy, which leads to a greater likelihood of being financially independent during young adulthood. Baumrind (1980) views socialization as an "adultinitiated process by which developing children, though insight, training, and imitation, acquire the habits and values congruent with adaptation to their culture." Parents and other family members can help socialize youth towards many positive behaviours and attitudes. For example, some researchers have found that teens who communicated often with their parents exhibited less risky sexual behaviours and were less likely to become school age mothers (Fox and Inazu, 1980) ${ }^{1}$. Communication in the family has also been shown to be an important factor in informing young people about economic matters. For example, the family is instrumental in teaching children about consumer behaviour and money management (Moschis and Moore, 1979; Moschis, 1985). In addition, Moschis and Moore (1984) find a relationship between family communication about consumption and adolescents' career decisions.

Family communication can occur in various ways, both overtly through social interaction, and covertly though role modeling and reinforcement (positive or negative) of behaviours (Moschis, 1985). To promote the transmission of attitudes and behaviours that foster financial independence, we submit that elements of the parents' work must be brought into the family arena, coming to the child's 
awareness and influencing the child's proximal experience. For example, some parents discuss their experiences on the job with one another in the presence of their children, and talk to their children about their work as well. Alternatively, parents may consider their employment as a more separate sphere, with little such discussion or activity penetrating into the family realm (Piotrkowski, 1978). In this study, we examine discussions about work that occur between family members and visits to parents' workplaces.

The division of family work is another experience that may affect economic socialization. Specifically, we assess the time the adolescent spent on regular chores in the home, and consider whether this work is done for pay. On the basis of their research in a rural setting, Elder and Conger (2000) note the potentially positive effects of regular chores, as well as paid work, in producing a sense of competence and importance, in mattering, and in fostering "integration into adult roles and self-conceptions." (91). The assignment of chores can establish a pattern of behaviour premised on the assumption of responsibility for self and others, an everyday experience of working as normal and expected, and a prelude to the similar assumption of economic responsibilities in adulthood. On the other hand, if doing chores promotes orientations and behaviours that enhance dependency and interfere with achievement outside the family, the implications for future financial independence may not be so sanguine.

Finally, we examine whether receipt of a regular allowance fosters economic efficacy and independence. Allowance is widely seen by parents as a form of economic education; through receiving a regular allowance, they believe that children will learn the value of money. Allowance may also be considered a prototypical exchange relation: often teenagers are expected to do their regular chores, get good grades, or display other positive childhood role enactments in order to receive their weekly or monthly stipends. It is therefore plausible that a regular allowance would have a positive influence on economic self-efficacy. However, if allowance is seen as a child's entitlement, it could establish a template of financial dependency that is unlikely to encourage economic independence. (For discussion of the various meanings of allowance, see Miller and Jung, 1990.)

\section{Data and Methods}

\section{Data Source}

The Youth Development Study (Mortimer 2003) began in 1988 with a randomly-chosen community sample of 1010 ninth graders enrolled in the St. Paul Public School District in Minnesota. United States Census data for 1980 indicate that this site was quite comparable to the nation as a whole with respect to economic and social indicators. The analyses reported here use data from student and parent surveys collected in 1988, when the respondents were freshmen in high school (mostly age 14 and 15), through the ninth wave of the study in 1997, six years after their scheduled graduation from high school, when they were 23 and 24 years old. This dataset is unique in its coverage of family socialization experiences, economic efficacy, transitions marking the onset of adult status, and economic independence. The longitudinal design represents a key asset in our study of the precursors and long-term consequences of economic self-efficacy. Whereas demographic information and other factual data may be measured accurately through retrospective recall, earlier experiences in the family of origin of interest to us here may have little psychological salience to young adults, and thus would be unlikely to be recalled. Any attempt to retrospectively measure adolescent self-efficacy would be quite suspect.

During the first four years of the study, corresponding to the high school period, participants completed questionnaires in their classrooms. If they were not present on either of the two survey administration days scheduled in each school, or if they were not attending school, they completed questionnaires by mail. Extensive tracking and follow-up procedures during each wave of data collection ensured that students who dropped out of school after ninth grade, or moved to another school district, continued to be followed. Data for the post-high school period, from 1992 on, were collected annually (except in 1996) via mailed surveys. Of the original 1010, 788 respondents completed surveys in 1997 . The retained sample in recent years is somewhat more advantaged than the initial sample in terms of family socioeconomic background and family composition (favouring the two-parent family), and retention has been more likely for females than males. Still, demographic, attitudinal, and experiential characteristics of the retained sample are quite similar to those of the initial panel (see Mortimer, 2003). Our analyses utilize data from the first, third, fourth, and ninth waves of the study; we select those respondents who 
participated in these waves and for whom full information on the variables used in the analysis was available. This yields an analytic sample of 617 respondents. We next describe the variables, which are reported in Table 1.

Table 1. Descriptive Statistics, Youth Development Study, 1988-1997 (N=617).

\begin{tabular}{|c|c|c|}
\hline & $\begin{array}{c}\text { mean/ } \\
\text { prop. }\end{array}$ & (s.d.) \\
\hline \multicolumn{3}{|l|}{ Background Variables (Wave 1-9th grade) } \\
\hline Gender $(1=$ male $)$ & 42.30 & -- \\
\hline Race (1=white) & 83.47 & -- \\
\hline Family Income & 6.08 & (2.32) \\
\hline Family Composition & 72.61 & -- \\
\hline \multicolumn{3}{|l|}{ Parents' Education } \\
\hline Less than High School & 11.81 & -- \\
\hline High School & 27.99 & -- \\
\hline Some College & 39.32 & -- \\
\hline College or More & 20.87 & -- \\
\hline Mother's Employment & 87.84 & -- \\
\hline Grade Point Average $(1=\mathrm{F}, 12=\mathrm{A})$ & 7.79 & (2.35) \\
\hline \multicolumn{3}{|c|}{ Family Socialization and Communication (Wave 3-11th Grade) } \\
\hline Hears Parents Discuss Work & 3.19 & (0.84) \\
\hline Discusses Work with Parents & 3.18 & (0.88) \\
\hline Visits Parents' Workplaces & 2.72 & (1.98) \\
\hline Hours per Week on Chores & 12.53 & (13.84) \\
\hline Paid Chores ( $1=$ yes) & 47.81 & -- \\
\hline Allowance Receipt $(1=$ yes $)$ & 77.15 & -- \\
\hline \multicolumn{3}{|l|}{ Dependent Variables } \\
\hline Economic Self-Efficacy (Wave 4-12th Grade) & 12.29 & (2.31) \\
\hline \multicolumn{3}{|l|}{ Status Attainments (Wave 9-Ages 23-24) } \\
\hline School Enrollment & 55.75 & -- \\
\hline Employment Status & 84.76 & -- \\
\hline Marital Status & 20.10 & -- \\
\hline Parenthood & 29.66 & -- \\
\hline High School or Less & 31.77 & -- \\
\hline Some College & 43.27 & -- \\
\hline College or More & 24.96 & -- \\
\hline Income (in thousands) & 13.86 & (10.08) \\
\hline Financial Independence (Wave 9-Ages 23-24) & 73.72 & (34.42) \\
\hline
\end{tabular}

\section{Key Independent Variables-Family Communication and Socialization towards Work}

We measure both covert and overt family communication about work. First, we considered how often the child hears his/her parents talk about work ("How often do you hear your parents [stepparents or guardians] talk about their jobs [with each other or with others]?") (1=never, $4=$ often). Second, we examined how often the parent talks with the child about his or her work ("How often does he [she] talk to you about his [her] work?") (1=never, $4=$ often). The highest value for the two parents was utilized; if 
the respondent had only one parent, that measure was used. We also consider visits to parents' workplaces, which is comprised of two indicators measuring how often the child visits the parent's workplace $(0=$ never, $6=$ more than once a week; again, we used the highest value) as a factor in socializing youth towards work. ${ }^{2} \mathrm{~A}$ unique feature of the Youth Development Study is a battery of questions about parents who do not live with the respondents. As a result, we were able to gain information about parents' work-related communications even for parents who did not live with the youth at the time of the survey. If respondents reported that they had two fathers or two mothers, e.g., a stepfather living with them and a biological father living apart, precedence was given to the parent who was living in the child's household.

As discussed earlier, we also consider other ways that youth can be socialized towards work. Time spent on chores was measured by the number of hours spent per week on household chores in the $11^{\text {th }}$ grade, and paid chores is a dichotomous variable indicating whether or not the adolescent was paid for doing these chores. A third measure of family socialization towards work is whether or not the youth had ever received an allowance.

\section{Dependent Variables}

We examine the development of economic self-efficacy during high school (measured in 1991 when the respondents were 17-18 years old and in the $12^{\text {th }}$ grade). The young people responded to a series of questions about the future (preceded by a lead-in question, "How do you see your future?").

Specifically, respondents were asked, "What are the chances that: You will have a job that pays well? You will have a job that that you enjoy doing? and You will be able to own your own home?" (Response options ranged from $5=$ Very high to $1=$ Very Low). Our measure of economic self-efficacy was created from these three items (alpha $=.80$ ). The mean of this composite measure of economic self-efficacy is 12.29 , suggesting that the respondents were rather optimistic about their futures. There was little difference between boys and girls in average levels of economic self-efficacy; however, girls tended to be more optimistic about their chances of having a job they enjoy doing in the future.

Next, we examine status attainments and markers of the transition to adulthood as mediating variables in the process of attaining financial independence. Specifically, we examine the impact of current school enrolment, employment status, marital status, parenthood, educational attainment, and income on financial independence, and how they are influenced by family socialization towards work and economic self-efficacy during the adolescent period. In our analysis sample, $56 \%$ were enrolled in school in 1997, $85 \%$ were employed, $20 \%$ were married, and $30 \%$ had at least one child. Thirty-two percent of the sample had a high school degree or less, $43 \%$ had completed some college, and $25 \%$ had obtained a college degree or higher. The average yearly income of employed respondents was about $\$ 16,350$ (if respondents were not employed, income was coded as 0 ; this reduced the average for the entire sample to $\$ 13,860$, shown in Table 1). ${ }^{3}$

Finally, we assess the young adults' financial independence by examining the percentage of their living expenses that came from either their own earnings or savings, or from their spouse or partner's earnings and/or savings, at age $23-24$. On average, a little less than three-quarters $(73.7 \%)$ of the respondents' expenses are covered by themselves or their spouses. Because this variable is skewed, we use its logged form as the dependent variable in our analyses.

\section{Control Variables}

For measures of family background, we draw on the 1988 parent survey for indicators of family socioeconomic status, including family income, parents' highest level of education, mother's employment, and family composition. Family income is an ordinal variable indicating total household income in $1987(0=$ less than $\$ 5,000,13=$ more than $\$ 100,000)$, parents' education is measured by dichotomous variables indicating the highest educational attainment of either parent (less than high school, high school, some college, or college or higher), mother's employment is a dichotomous variable indicating whether or not the adolescent's mother was currently employed ( $1=$ employed), and family composition indicates whether the child lives with two parents. Dichotomous variables indicating race $(1=$ white $)$ and gender $(1=$ male $)$ of the respondent were also included in the analyses. Last, we control for grade point average in the $9^{\text {th }}$ grade $(1=F, 12=A)$. 


\section{Results}

\section{Economic Self-Efficacy}

Table 2 presents results from an Ordinary Least Squares (OLS) regression of economic self-efficacy during adolescence. Model 1 is the baseline model that examines the effects of family background and grade point average on economic self-efficacy in the $12^{\text {th }}$ grade. Model 2 examines the influences of communication within the family and socialization towards work without taking into consideration background factors. ${ }^{4}$ Last, Model 3 includes both background characteristics and family socialization in order to assess the independent associations between socialization towards work and economic selfefficacy above and beyond differences in gender, race, family socioeconomic status, and prior academic achievement. $^{5}$

Our analysis of economic self-efficacy during high school suggests that more advantaged youth, in terms of family background and academic performance, exhibit more confidence about their economic future. Model 1 shows that family background and grades significantly affect economic self-efficacy during high school. Family income exerts a weak positive influence $(p<0.10)$ and parents' education also has a positive effect on economic self-efficacy in high school. Children whose parents had some college education have higher efficacy than those whose parents had less than a high school education. ${ }^{6}$ Higher academic achievement is associated with higher levels of economic self-efficacy.

As shown in Model 2, some early socialization experiences in the family can impact an adolescent's beliefs about his or her economic capacity. Specifically, the more the child talks with his or her parents about their work, the greater his/her economic self-efficacy during high school. Surprisingly, however, other forms of family communication about work, such as visiting a parent's workplace and hearing the parents talk about work amongst themselves or with others do not influence economic self-efficacy. These findings suggest that direct communication about work between the parent and child might be the most effective form of socialization when it comes to shaping adolescents' perceptions of their own capacities to be successful in the economic realm. Other economic activities within the home can also shape one's economic self-efficacy. Consistent with Elder and Conger's (2000) findings, doing chores for pay is associated with somewhat greater economic self-efficacy $(p<.10)$. Contrary to our initial hypothesis, however, we find that youths who received an allowance have lower levels of economic self-efficacy. The zero-order correlation between regular allowance receipt and economic self-efficacy is negative, which suggests that allowance may come to be perceived as a kind of entitlement, with connotations of economic dependency rather than efficacy.

Model 3 shows that the influence of family socialization towards work on economic self-efficacy cannot be fully explained by initial differences in background and prior academic performance. Net of family background and grades, parent-child discussions related to work still exert a positive influence on an adolescent's sense of future economic success, and those who ever received an allowance had lower levels of self-efficacy than those who did not. 
Table 2. Regression of Economic Self-Efficacy on Family Socialization towards Work

\begin{tabular}{|c|c|c|c|c|c|c|c|c|c|}
\hline & & del 1 & & Moc & del 2 & & & del 3 & \\
\hline & $\mathrm{b}$ & (s.e.) & & $\mathrm{b}$ & (s.e.) & & $\mathrm{b}$ & (s.e.) & \\
\hline Background Variables & & & & & & & & & \\
\hline Gender ( $1=$ male $)$ & 0.13 & (0.19) & & -- & -- & & 0.11 & $(0.19)$ & \\
\hline Race (1 = white) & -0.25 & $(0.25)$ & & -- & -- & & -0.39 & $(0.25)$ & \\
\hline Family Income & 0.08 & $(0.05)$ & + & -- & -- & & 0.08 & $(0.05)$ & + \\
\hline Family Composition & 0.05 & $(0.23)$ & & -- & -- & & -0.04 & $(0.23)$ & \\
\hline Parent High School & 0.28 & $(0.27)$ & & -- & -- & & 0.27 & $(0.26)$ & \\
\hline Parent Some College & 0.70 & $(0.27)$ & ** & -- & -- & & 0.69 & $(0.27)$ & * \\
\hline Parent College or More & 0.46 & $(0.31)$ & & -- & -- & & 0.43 & $(0.32)$ & \\
\hline Mother's Employment & 0.04 & $(0.28)$ & & -- & -- & & -0.27 & $(0.31)$ & \\
\hline G.P.A. & 0.18 & $(0.04)$ & $* * *$ & -- & -- & & 0.16 & $(0.04)$ & *** \\
\hline Family Socialization and Comm & & & & & & & & & \\
\hline Hears Parents Discuss Work & -- & -- & & -0.05 & $(0.13)$ & & -0.10 & $(0.13)$ & \\
\hline Discusses Work with Parents & -- & -- & & 0.33 & $(0.13)$ & * & 0.32 & $(0.14)$ & $*$ \\
\hline Visits Parents' Workplaces & -- & -- & & 0.01 & $(0.05)$ & & 0.00 & $(0.05)$ & \\
\hline Hours per Week on Chores & -- & -- & & -0.01 & $(0.01)$ & & 0.00 & $(0.01)$ & \\
\hline Paid Chores ( $1=$ yes) & -- & -- & & 0.49 & $(0.26)$ & + & 0.31 & $(0.26)$ & \\
\hline Allowance Receipt ( $1=$ yes) & -- & -- & & -0.52 & $(0.23)$ & $*$ & -0.55 & $(0.22)$ & $*$ \\
\hline Intercept & 10.13 & $(0.51)$ & & 11.80 & $(0.43)$ & & 10.38 & $(0.61)$ & \\
\hline R-square & 0.07 & & & 0.03 & & & 0.09 & & \\
\hline
\end{tabular}

$+p<0.10,{ }^{*} p<0.05,{ }^{* *} p<0.01,{ }^{* * *} p<0.001$

\section{The Transition to Adulthood}

The transition to adulthood is often marked by events such as the completion of schooling, starting a career, marrying, and having children. We suggest that not only are these potentially intervening factors in the attainment of financial independence, but that they might also be influenced by economic selfefficacy. Using logistic regression, we next assess the influences of economic self-efficacy on current school enrollment, employment status, marital status, and parenthood. ${ }^{7}$ Results from these analyses are presented in Table 3.

The results, shown in Model 1 for each analysis, are consistent with prior research in that we find that young adults with more socioeconomically advantaged family backgrounds are more likely to still be enrolled in school and tend to delay marriage and parenthood. As of age 23-24, individuals with more highly educated parents are more likely to be enrolled in higher education and less likely to have had children than those whose parents have less than a high school degree. Those with higher family incomes during high school are less likely to be married or parents by 23-24. Males are more likely to be employed than females, and are less likely to have had a child. In addition, young adults with higher grade point averages in high school have higher odds of school enrollment and of being employed, whereas they have lower odds of having a child.

We also find that economic self-efficacy during adolescence has long-term influences on some facets of the transition to adulthood, independent of family background advantages and educational performance during high school. In particular, the greater one's self-efficacy during high school, the higher the odds that he or she will be employed, and the lower the odds he or she will have had at least one child by age 23-24 (see Model 2 across these variables). Thus, while economic self-efficacy increases the likelihood of working during young adulthood, it also tends to "delay" other facets of the transition to adulthood by postponing the onset of parenthood. Even though economic self-efficacy does not appear to influence school enrollment at age 23-24, the results presented in Table 4 indicate that it is positively related to educational attainment. This pattern suggests that perhaps those with the greatest economic self-efficacy have already completed higher education by early adulthood. 
Table 3. Logistic Regressions of the Transition to Adulthood on Background and Economic Self-Efficacy

\begin{tabular}{|c|c|c|c|c|c|c|c|c|c|c|c|c|c|}
\hline \multirow[b]{4}{*}{ Background Variables } & \multicolumn{7}{|c|}{ In school } & \multicolumn{6}{|c|}{ Employed } \\
\hline & \multicolumn{4}{|c|}{ Model 1} & \multicolumn{3}{|c|}{ Model 2} & \multicolumn{2}{|c|}{ Model 1} & & \multicolumn{3}{|c|}{ Model 2} \\
\hline & $\mathrm{b}$ & (s.e.) & \multicolumn{2}{|c|}{$\exp (b)$} & b (s.e.) & \multicolumn{2}{|c|}{$\exp (b)$} & $\mathrm{b}$ & (s.e.) $\exp (\mathrm{b})$ & & $\mathrm{b}$ & \multicolumn{2}{|l|}{ (s.e.) $\exp (b)$} \\
\hline & & & & & & & & & & & & & \\
\hline Gender ( $1=$ male $)$ & 0.23 & $3(0.18)$ & 1.26 & & $0.22(0.18)$ & 1.25 & & 0.90 & $(0.26) 2.46$ & $* * *$ & 0.88 & $(0.26) 2.41$ & ** \\
\hline Race (1 = white) & -0.22 & $(0.24)$ & 0.80 & & $-0.21(0.24)$ & 0.81 & & 0.46 & (0.29) 1.58 & & 0.48 & $(0.29) 1.62$ & + \\
\hline Family Income & 0.05 & $5(0.05)$ & 1.05 & & $0.04(0.05)$ & 1.04 & & 0.12 & $(0.06) 1.12$ & + & 0.11 & $(0.06) 1.11$ & + \\
\hline Family Composition & 0.23 & $(0.23)$ & 1.26 & & $0.23(0.23)$ & 1.26 & & 0.21 & $(0.28) 1.23$ & & 0.20 & $(0.29) 1.22$ & \\
\hline Parent High School & -0.17 & $(0.25)$ & 0.85 & & $-0.18(0.25)$ & 0.83 & & 0.09 & $(0.33) 1.09$ & & 0.05 & (0.34) 1.05 & \\
\hline Parent Some College & 0.73 & $(0.25)$ & 2.09 & $* *$ & $0.70(0.26)$ & 2.01 & $* *$ & -0.06 & (0.33) 0.95 & & -0.16 & $(0.34) 0.86$ & \\
\hline Parent College or More & 1.16 & $(0.32)$ & 3.19 & $* * *$ & $1.14(0.32)$ & 3.12 & $* * *$ & -0.35 & (0.40) 0.71 & & -0.42 & $(0.40) 0.66$ & \\
\hline Mother's Employment & -0.08 & $3(0.27)$ & 0.92 & & $-0.08(0.27)$ & 0.92 & & 0.08 & (0.36) 1.08 & & 0.06 & $(0.36) 1.07$ & \\
\hline G.P.A. & 0.26 & $(0.04)$ & 1.30 & $* * *$ & $0.25(0.04)$ & 1.28 & $* * *$ & 0.18 & $(0.05) 1.20$ & $* * *$ & 0.17 & (0.05) 1.18 & $* *$ \\
\hline Economic Self-Efficacy & - & -- & & & $0.06(0.04)$ & 1.06 & & - & - & & 0.12 & $(0.05) 1.12$ & $*$ \\
\hline Intercept & -2.45 & $(0.51)$ & & & $-3.03(0.65)$ & & & -1.17 & $(0.60)$ & & -2.34 & $(0.78)$ & \\
\hline Chi-square & & 114.10 & & & 116.15 & & & & 39.23 & & & 44.72 & \\
\hline Degrees of Freedom & & 9 & & & 10 & & & & 9 & & & 10 & \\
\hline
\end{tabular}

$+\mathrm{p}<0.10,{ }^{*} \mathrm{p}<0.05,{ }^{* *} \mathrm{p}<0.01,{ }^{* * *} \mathrm{p}<0.001$

Table 3 Cont. Logistic Regressions of the Transition to Adulthood on Background and Economic Self-Efficacy

\begin{tabular}{|c|c|c|c|c|c|c|c|c|c|c|c|c|}
\hline & \multicolumn{7}{|c|}{ Marital Status } & \multicolumn{5}{|c|}{ Parenthood } \\
\hline & \multicolumn{4}{|c|}{ Model 1} & \multicolumn{2}{|c|}{ Model 2} & & \multicolumn{2}{|c|}{ Model 1} & \multicolumn{3}{|c|}{$\begin{array}{l}\text { Model } 2 \\
\text { (s.e.) exp(b) }\end{array}$} \\
\hline \multicolumn{13}{|l|}{ Background Variables } \\
\hline Gender (1=male) & -0.14 & $(0.21)$ & 0.87 & & $-0.14(0.21)$ & 0.87 & & -0.73 & $3(0.21) 0.48 * * *$ & -0.72( & $(0.21) 0.49$ & $* * *$ \\
\hline Race (1=white) & 0.35 & $(0.29)$ & 1.42 & & $0.36(0.29)$ & 1.44 & & -0.55 & $5(0.25) 0.58$ & $-0.58 \mid$ & (0.25) 0.56 & * \\
\hline Family Income & -0.13 & $(0.06)$ & 0.88 & * & $-0.14(0.06)$ & 0.87 & * & -0.21 & $(0.06) 0.81 * * *$ & -0.201 & $(0.06) 0.82$ & $* * *$ \\
\hline Family Composition & 0.04 & $(0.25)$ & 1.05 & & $0.04(0.25)$ & 1.04 & & -0.12 & $2(0.24) 0.88$ & -0.111 & (0.24) 0.89 & \\
\hline Parent High School & 0.21 & $(0.29)$ & 1.24 & & $0.20(0.29)$ & 1.22 & & 0.02 & $2(0.26) 1.02$ & 0.041 & $(0.26) 1.04$ & \\
\hline Parent Some College & 0.17 & $(0.29)$ & 1.18 & & $0.13(0.30)$ & 1.14 & & -0.23 & $3(0.27) 0.80$ & $-0.17 \mid$ & (0.27) 0.85 & \\
\hline Parent College or More & -0.21 & $(0.37)$ & 0.81 & & $-0.23(0.37)$ & 0.79 & & -1.23 & $(0.40) 0.29 * *$ & -1.19 ( & $(0.40) 0.30$ & $* *$ \\
\hline Mother's Employment & -0.22 & $(0.30)$ & 0.80 & & $-0.22(0.30)$ & 0.80 & & 0.09 & $(0.30) 1.09$ & 0.101 & $(0.31) 1.10$ & \\
\hline G.P.A. & -0.01 & $(0.04)$ & 0.99 & & $-0.02(0.05)$ & 0.98 & & -0.24 & $(0.04) 0.79 * * *$ & -0.221 & $(0.04) 0.80$ & $* * *$ \\
\hline Economic Self-Efficacy & - & -- & & & $0.04(0.05)$ & 1.05 & & - & -- & -0.08 ( & $(0.04) 0.92$ & $*$ \\
\hline Intercept & -0.66 & $(0.55)$ & & & $-1.11(0.73)$ & & & & $3.06(0.55)$ & & $3.93(0.71)$ & \\
\hline Chi-square & & 14.43 & & & 15.39 & & & & 121.23 & & 125.07 & \\
\hline Degrees of Freedom & & 9 & & & 10 & & & & 9 & & 10 & \\
\hline
\end{tabular}

$+p<0.10,{ }^{*} p<0.05,{ }^{* *} p<0.01,{ }^{* * *} p<0.001$ 


\section{Status Attainment}

Another mechanism through which economic efficacy could impact financial independence is through one's own status attainments, specifically educational attainment and income. In Table 4, we present the results of a multinomial logistic regression of educational attainment (with high school or less as the reference category), and in Table 5, we report the results of an OLS regression of income. Our findings for both of these outcomes are consistent with classic research on status attainment. Higher family income and parents' education are associated with increased odds of completing at least some college or more as opposed to a high school degree. Additionally, men earn more then women, and whites earn more than non-whites. Somewhat unexpectedly, parents' education has a negative effect on young adult income. The negative relationship between parents' education and income in 1997 is probably due to the fact that those with more educated parents are also more likely to still be enrolled in school themselves, as shown in Table 3. Not surprisingly, grade point average in high school is also positively associated with educational attainment in young adulthood.

Table 4. Multinomial Logistic Regression of Educational Attainment on Background and Economic Self-Efficacy

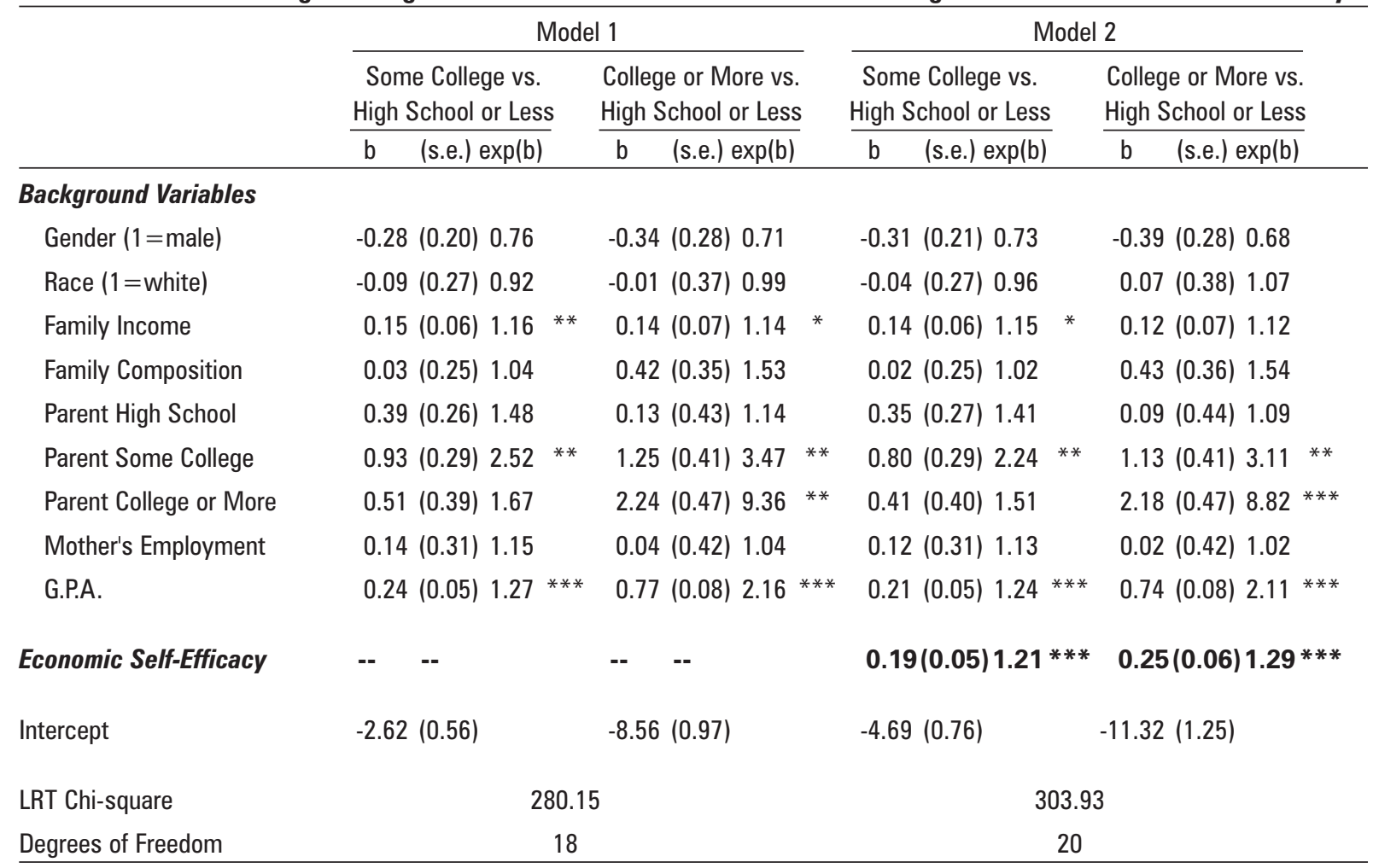

$+p<0.10,{ }^{*} p<0.05,{ }^{* *} p<0.01,{ }^{* *} p<0.001$

Even after accounting for these effects of family background and grades on status attainment, we still see a positive relationship between economic self-efficacy during high school and educational attainment and income. Similar to the findings of Grabowski et al, (2001), Model 2 in Table 4 shows that including economic self-efficacy significantly contributes to the overall model fit. A greater sense of efficacy in the economic realm increases both the odds of completing some college and the odds of completing college or more, as opposed to completing a high school degree or less. In addition to its positive influence on educational attainment, we also find that economic self-efficacy in adolescence is quite beneficial for income attainment in young adulthood, as shown in Table 5. These results suggest that early development of self-confidence in one's own economic capacity has long term benefits for status attainment, net of family background and academic performance. 
Table 5. Regression of Income on Background and Economic Self-Efficacy

\begin{tabular}{|c|c|c|c|c|c|c|}
\hline & \multicolumn{3}{|c|}{ Model 1} & \multicolumn{3}{|c|}{ Model 2} \\
\hline & $\mathrm{b}$ & (s.e.) & & $b$ & (s.e.) & \\
\hline \multicolumn{7}{|l|}{ Background Variables } \\
\hline Gender ( $1=$ male $)$ & 2.06 & $(0.78)$ & $* * *$ & 2.09 & $(0.77)$ & $* *$ \\
\hline Race (1=white) & 2.05 & (1.09) & $* *$ & 2.08 & (1.08) & \\
\hline Family Income & 0.38 & $(0.21)$ & & 0.34 & $(0.21)$ & \\
\hline Family Composition & -1.51 & (1.01) & & -1.52 & $(1.00)$ & \\
\hline Parent High School & -0.76 & $(1.13)$ & & -0.93 & $(1.12)$ & \\
\hline Parent Some College & -2.14 & (1.14) & & -2.46 & $(1.13)$ & * \\
\hline Parent College or More & -3.75 & (1.33) & $* *$ & -3.98 & $(1.33)$ & ** \\
\hline Mother's Employment & -0.32 & (1.19) & & -0.45 & (1.18) & \\
\hline G.P.A. & 0.30 & $(0.18)$ & & 0.20 & $(0.19)$ & \\
\hline Economic Self-Efficacy & - & - & & 0.53 & $(0.18)$ & ** \\
\hline Intercept & 11.97 & $(2.27)$ & & 6.66 & $(2.88)$ & \\
\hline R-square & \multicolumn{3}{|c|}{0.04} & \multicolumn{2}{|c|}{0.06} & \\
\hline
\end{tabular}

${ }^{*} \mathrm{p}<0.05,{ }^{* *} \mathrm{p}<0.01,{ }^{* * *} \mathrm{p}<0.001$

\section{Financial Independence}

The question of what factors foster financial independence in young adulthood still remains. We now turn to the influences of economic self-efficacy during adolescence on financial independence. The results of this analysis are presented in Table 6. Model 1 assesses the role of family background and grades on the logged percent of expenses that are covered by the respondent and his/her spouse. Model 2 adds economic self-efficacy in order to assess its independent contribution to financial independence net of the effects of family background and educational performance. Finally, Model 3 examines whether any of these relationships are mediated through status attainment and/or other markers of the transition to adulthood. Because it is plausible to assume that the process of achieving financial independence would differ for males and females, we estimated interactions of gender with economic efficacy, the family socialization and communication indicators, and the Wave 9 attainments. Therefore, Model 3 also includes interactions between gender and employment status, marital status, and parenthood. ${ }^{8}$

The results from Model 1 indicate that background factors have little effect on financial independence in young adulthood. It is interesting to note that more advantaged youth are no more or less financially independent at the age of 23-24 than those who grew up in more socioeconomically disadvantaged households, and that being financially self-reliant is not associated with early academic performance. Instead, the strongest background predictors of financial independence are gender and race. Males report greater financial independence than females, and whites are more economically self-sufficient than non-whites.

Model 2 shows that early adult financial independence is positively associated with economic selfefficacy during adolescence. Those who felt more efficacious when it came to their economic futures were indeed more likely to be financially self-reliant by age 23 or 24 . It is notable that this construct, measured in the senior year of high school, is still associated with financial independence so many years later, even when controlling for relevant background factors. 
Table 6. Regression of Financial Independence on Background, Economic Self-Efficacy, and Attainments

\begin{tabular}{|c|c|c|c|c|c|c|c|c|c|}
\hline \multirow{3}{*}{ Background Variables } & \multirow{2}{*}{\multicolumn{3}{|c|}{$\begin{array}{l}\text { Model } 1 \\
b^{\text {(s.e.) }}\end{array}$}} & \multirow{2}{*}{\multicolumn{3}{|c|}{$\begin{array}{l}\text { Model } 2 \\
\text { b (s.e.) }\end{array}$}} & \multicolumn{3}{|c|}{ Model 3} \\
\hline & & & & & & & \multirow[t]{2}{*}{$\mathrm{b}$} & \multicolumn{2}{|l|}{ (s.e.) } \\
\hline & & & & & & & & & \\
\hline Gender (1=male) & 0.34 & $(0.11)$ & $* *$ & 0.33 & $(0.11)$ & $* *$ & 1.07 & $(0.28)$ & *** \\
\hline Race (1 = white) & 0.29 & $(0.14)$ & * & 0.31 & (0.14) & * & 0.10 & $(0.12)$ & \\
\hline Family Income & 0.02 & $(0.03)$ & & 0.01 & $(0.03)$ & & -0.01 & $(0.02)$ & \\
\hline Family Composition & 0.00 & $(0.13)$ & & 0.00 & $(0.13)$ & & -0.01 & $(0.11)$ & \\
\hline Parent High School & 0.01 & $(0.15)$ & & -0.02 & $(0.15)$ & & -0.07 & $(0.13)$ & \\
\hline Parent Some College & -0.06 & $(0.15)$ & & -0.12 & $(0.15)$ & & -0.08 & $(0.13)$ & \\
\hline Parent College or More & -0.15 & $(0.18)$ & & -0.19 & (0.18) & & -0.09 & $(0.16)$ & \\
\hline Mother's Employment & -0.22 & $(0.16)$ & & -0.23 & $(0.16)$ & & -0.14 & $(0.14)$ & \\
\hline G.P.A. & 0.00 & $(0.02)$ & & -0.01 & $(0.02)$ & & -0.06 & $(0.02)$ & * \\
\hline Economic Self-Efficacy & -- & - & & 0.08 & $(0.02)$ & $* * *$ & 0.03 & $(0.02)$ & \\
\hline \multicolumn{10}{|l|}{ Wave 9 Attainments } \\
\hline School Enrollment & -- & -- & & -- & -- & & -0.35 & $(0.12)$ & $* *$ \\
\hline Employment Status & -- & -- & & -- & -- & & 1.34 & $(0.18)$ & *** \\
\hline Marital Status & -- & -- & & -- & -- & & 0.84 & $(0.15)$ & *** \\
\hline Parenthood & -- & -- & & -- & -- & & -0.41 & $(0.15)$ & $* *$ \\
\hline Income & -- & -- & & -- & -- & & 0.03 & (0.01) & *** \\
\hline Some College & -- & -- & & -- & -- & & 0.23 & $(0.12)$ & + \\
\hline College or More & -- & -- & & -- & -- & & 0.49 & (0.18) & $* *$ \\
\hline Gender x Employment Status & -- & -- & & -- & -- & & -1.10 & $(0.29)$ & $* * *$ \\
\hline Gender x Marital Status & -- & -- & & -- & -- & & -0.58 & $(0.24)$ & * \\
\hline Gender x Parenthood & -- & -- & & -- & -- & & 0.66 & $(0.22)$ & $* *$ \\
\hline Intercept & 3.66 & $(0.30)$ & & 2.83 & $(0.38)$ & & 2.64 & $(0.37)$ & \\
\hline R-square & 0.03 & & & 0.05 & & & 0.32 & & \\
\hline
\end{tabular}

$+p<0.10,{ }^{*} p<0.05,{ }^{* *} p<0.01,{ }^{* * *} p<0.001$

Model 3, however, indicates that the markers of the transition to adulthood and status attainments mediate the relationship between economic self-efficacy and financial independence in young adulthood. First, as shown earlier, economic self-efficacy formed during high school increases the odds of employment (Table 3); this in turn increases financial independence, especially among women.

Second, economic self-efficacy decreases the odds of having at least one child by age 23-24 (Table 3), which is negatively related to financial independence for women. Third, higher adolescent economic self-efficacy increases educational attainment and income (Tables 4 and 5), which are associated with greater independence in supporting oneself. These findings suggest that although economic selfefficacy contributes to the accomplishment of financial independence, its influence is primarily indirect, through the youth's own status attainments. The significant interactions indicate that the process of attaining financial independence differs for men and women. Young adult women are more dependent on marriage and employment for financial self-sufficiency than are men (i.e., the effect of marriage is .84 for women, but only .26 [.84-.58] for men; the effect of employment is 1.34 for women, but only .24 [1.34-1.10] for men). Parenthood, in contrast, lessens females' independence (-.41), while increasing it somewhat for men $(-.41+.66=.25)$. 


\section{Discussion}

This paper has examined the role of family socialization towards work in adolescence in fostering economic self-efficacy, and the subsequent influence of self-efficacy on the transition to adulthood, status attainment, and financial independence in young adulthood. From this research, it appears that for young adults, experiences in the family that increase the salience of market work - that is, communicating with one's parents about their work - foster a sense of confidence in the economic realm. A household climate that emphasizes verbal communication about work between family members, including discussions with fathers and mothers, is likely to increase the psychological salience of work to adolescents. Their own anticipation of being effective in the economic sphere is thereby heightened. In addition, we find that self-efficacy has a direct impact on financial independence in young adulthood though educational and occupational attainments as well as the delay of family formation in the early 20 s.

This paper sets forth preliminary evidence that the development of economic competency is a longterm process that commences through experiences in the family setting, well before the onset of adulthood. Socialization towards work in the family context appears to indirectly enhance young adults' capacities to support themselves. The overall pattern of findings suggests that micro-level interpersonal relations and interactions may be key to understanding the processes through which families foster the economic self-efficacy and independence of their children. These findings point to the potential for positive work-family linkages. Parents can indeed promote the development of economic self-efficacy in their teenage children by enabling their work to influence what goes on at home, by talking about their jobs to their children. In some circumstances, for example, in entrepreneurial settings or on the farm (Elder and Conger, 2000) the blurring of the boundaries between work and home may occur very naturally, encouraging interactions about work. In large bureaucratic settings, there may be days set aside for children to be brought to work. Other settings (particularly those that may be highly regulated, highly technical, or dangerous) may be less "family-" or "child-friendly." No matter what the setting, informal socialization towards work, like just talking about work, can have positive consequences for adolescents' confidence about their financial futures and their actual capacities to become economically independent in early adulthood. The findings raise caution, however, about potentially adverse effects of monetary exchanges in the family. Contrary to many parents' beliefs, and prescriptive advice to give children a regular allowance in the family guidance literature, we find that those who ever received an allowance were less economically efficacious in adolescence than those who did not receive this regular stipend; moreover, allowance receipt was associated with restricted educational attainment.

This study has some noteworthy limitations. First, all data (except the socio-economic background variables) were obtained from the young people themselves. Much better understanding of the family dynamics that foster economic independence would be obtained if parents' own orientations could be taken into account. While there is some understanding of parent's views with respect to the purposes of allowance (Miller and Jung, 1990), we know little about parents' intentions with respect to communications about work, or about the reasons for assigning chores. For example, do parents who have higher occupational aspirations for their children deliberately make a point of talking to them about their work? Do parents who give their children allowance or offer money in exchange for chores encourage financial dependency in other ways? Even though we know the frequency of parent-child discussion about work, we know nothing of the content of these communications. They may involve direct encouragement of economic self-efficacy in children, or they may provide other messages from which adolescents derive this positive self-concept. More direct study of parental intentions and the content of family interactions, surrounding both market work and housework, would enable assessment of whether the communications among family members observed here mediate important differences in parental goals.

Despite the limitations of this study and the further questions remaining, the long duration of this project, with surveys spanning a highly formative period of economic socialization and attainment, has enabled us to observe the impacts of family and work experiences as they occur, rather than relying on retrospective recall. The findings highlight the significant influence of economic socialization in the family setting on the development of an adolescent's confidence in his/her economic capacities, which paves the way for adult financial independence. It is especially noteworthy that in this study six years separated the measurement of economic efficacy and the outcomes of interest; economic efficacy was measured at age 17-18, the status transitions and attainments, at age 23-24. The findings demonstrate 
the enduring significance of economic self-efficacy in assuring a successful transition to adult roles and the achievement of economic independence. The more efficacious adolescents were more likely to be employed in early adulthood; they also had higher educational attainment and income. Furthermore, adolescent economic efficacy was associated with a delay in parenthood, enabling the more efficacious youth to invest more in their human capital through higher education. Whereas economic efficacy had a positive relationship to economic independence, this relationship was entirely mediated by the transitions and attainments that led to financial self-sufficiency.

It might be countered that self-efficacy in adolescence should not be considered to have causal force. Instead, those adolescents, on the basis of their socioeconomic backgrounds and associated advantages, simply understand that they are likely to have more positive economic futures than those facing greater obstacles. According to this view, the relationship between efficacy and the outcomes we have studied is spurious. This argument parallels a long-standing criticism of studies that prioritize psychological orientations more generally, including aspirations, as determinants of educational and occupational attainments (Roberts, 1968). Achievement-related orientations are seen as having no causal role in the process of attainment; they are instead mere products of actual achievements and more or less advantaged social location. While this position is plausible, the fact that numerous indicators of advantage and achievement are controlled in our analysis appears to undermine such criticism. Even with gender, race, family income, family composition, and parental education controlled, we still find that adolescent self-efficacy is positively related to educational attainment, employment, and income in early adulthood. The adolescent's grade point average is, as might be expected, also a significant influence on these positive outcomes, but this indicator of ability and academic performance is also controlled. The findings indicate that efficacy is, in fact, an important resource for the transition to adulthood and for the processes of socioeconomic attainment that promote early adult economic sufficiency. They call for more active interventions on the part of the family, as well as other institutions, to stimulate positive self-conceptions of efficacy in the workplace so as to enhance socioeconomic attainments and foster financial independence.

We recognize that institutional structures and changes, including trends in educational enrollment and financing, labour market opportunities, welfare policies, and taxation mechanisms (Smeeding and Phillips, 2002), are of critical importance, influencing the likelihood that individuals will experience economic difficulties during the transition to adulthood as well as at other junctures in their lives. Such macro-level phenomena give rise to the societal distribution of income, the prevalence of poverty in any given historical period, and the effectiveness of various asset accumulation strategies for particular social groups (Shapiro and Wolff, 2001). Moreover, the effectiveness of individual agentic processes importantly varies across time and place depending on the configuration of structural opportunities (Shanahan, Elder, and Miech, 1997). Nonetheless, we contend that a full understanding of financial independence, along with other forms of adaptation to the challenges of adulthood, requires consideration of both structure and agency. The capacity of individuals to take advantage of the particular, historically-specific opportunities available to them as they make the transition to adulthood, and to surmount the obstacles that they encounter in seeking their economic goals, will depend on a multitude of resources, including psychological assets and behavioural patterns acquired during the course of their prior development.

\section{Endnotes}

${ }^{1}$ Moore, Peterson and Furstenberg (1986) find that that this is only the case for daughters of parents with traditional values.

${ }^{2}$ We examined whether a family socialization index comprised of these single indicators (hearing parents talk about work, discussing work with parents, and visiting parents' workplaces) would be more appropriate; however, their low alpha reliability $(0.50)$ suggested that they should be analyzed separately in our model.

${ }^{3}$ It would be interesting to consider household income as well as personal income, given that our measure of financial independence also includes spouses' earnings. However, information on household income is not available in the data for 1997.

${ }^{4}$ We also examined whether family communication about work over time (measured by an average over 9th, 10th, and 11th grades) impacted economic self-efficacy. This analysis yielded similar results. 
${ }^{5}$ We also tested for interactions between gender and family socialization. The effects were not statistically significant, suggesting that the relationship between family socialization and communication and economic self-efficacy in adolescence is similar for boys and girls.

${ }^{6}$ When grade point average is not included in the equation, children of parents with a four-year college degree or more also have higher efficacy than those whose parents had the lowest level of education. The pattern suggests that the most highly educated parents increase their children's self-efficacy by fostering high grade point averages.

7 In preliminary analyses, we found that family socialization towards work is not correlated with the transition to adulthood and financial independence beyond its relationship with economic selfefficacy. Thus, for parsimony, these variables are omitted from subsequent models.

8 We initially included interactions between gender and all indicators of the transition to adulthood; we present only those that are statistically significant.

\section{References}

Aquilino WS (2005) Impact of Family Structure on Parental Attitudes toward the Economic Support of Adult Children Over the Transition to Adulthood. Journal of Family Issues, 26: 143-167.

Arnett J (1994) Are College Students Adults? Their Conceptions of the Transition to Adulthood. Journal of Adult Development 1: 154-168.

Arnett J (1998) Learning to Stand Alone: The Contemporary American Transition to Adulthood in Cultural and Historical Context. Human Development 41: 295-315.

Bandura A (1997) Self-Efficacy: The Exercise of Control. New York: Freeman.

Baumrind D (1980) New Directions in Socialization Research. American Psychologist, 7: 639-652.

Bynner, J (1998) Education and Family Components of Identity in the Transition from School to Work. International Journal of Behavioural Development 22:29-54.

Bynner, J, Parsons, S (2002) Social Exclusion and the Transition from School to Work: The Case of Young People Not in Education, Employment, or Training. Journal of Vocational Behaviour 60: 289-309.

Caplan L J, Schooler C (2007) Socioeconomic Status and Financial Coping Strategies: The Mediating Role of Perceived Control. Social Psychology Quarterly 70: 43-58.

Christie H, Munro, M, Rettig, H. (2002) Working all the Time: Student Incomes and Employment. Youth \& Policy 78: 1-25.

Elder G. H, Jr., Conger R D. (2000) Children of the Land: Adversity and Success in Rural America. Chicago: University of Chicago Press.

Featherman D L (1980) Schooling and Occupational Careers: Constancy and Change in Worldly Success. In Brim O G, Kagan J eds. Pp. 675-738 in Constancy and Change in Human Development. Pp. 675-738. Cambridge: Harvard University Press.

Fox G L, Inazu J K. (1980) Mother-Daughter Communication about Sex. Family Relations, 29: 347-352.

Furstenberg F, Jr., Kennedy S, McCloyd V C, Rumbaut R G, and Settersten R A, Jr. (2003) Between Adolescence and Adulthood: Expectations about the Timing of Adulthood. Network on Transitions to Adulthood and Public Policy Working Paper No. 1.

Goldscheider F. K., Goldscheider C (1994) Leaving and Returning Home in 20th Century America. Population Bulletin 48(4): 2-33.

Grabowski L S, Call, K T and Mortimer JT. (2001) Global and Economic Self-Efficacy in the Educational 
Attainment Process. Social Psychology Quarterly 64: 164-179.

Haveman, R, Wolfe B (1994) Succeeding Generations. On the Effects of Investments in Children. New York: Russell Sage Foundation.

Heinz W R (2003) From Work Trajectories to Negotiated Careers: The Contingent Work Life Course. In Mortimer JT, Shanahan, MJ eds. Handbook of the Life Course, Pp. 185-204. New York: Kluwer Academic/Plenum Publishers.

Keister L A (2003) Sharing the Wealth: The Effect of Siblings on Adults' Wealth Ownership, Demography 40: $521-542$

King T and Bannon E (2002) The Burden of Borrowing: A Report on the Rising Rates of Student Loan Debt. The State PIRGs' Higher Education Project. U.S. District of Columbia.

Kohli M. (2003) Intergenerational Family Transfers in Aging Societies. Section on Aging and the Life Course Distinguished Scholar Lecture. Annual Meeting of the American Sociological Association. Washington, D. C.

Kohn M L (1981) Personality, Occupation, and Social Stratification: A Frame of Reference. In Treiman. D J, Robinson RV eds. Research in Social Stratification and Mobility, Vol. 1, Pp. 267-297. Greenwich, CT: JAI Press.

Kohn M L, Schooler C (1983) Work and Personality: An Inquiry into the Impact of Social Stratification. Norwood, NJ: Ablex.

Miller J, Jung S (1990) The Role of Allowances in Adolescent Socialization. Youth and Society 22: 137159.

Mortimer J T (1976) Social Class, Work, and the Family: Some Implications of the Father's Occupation for Familial Relationships and Sons' Career Decisions. Journal of Marriage and the Family 38: 241-254.

Mortimer J T (2003) Working and Growing Up in America. Cambridge: Harvard University Press.

Mortimer J T, Kumka, D S (1982) A Further Examination of the 'Occupational Linkage Hypothesis'. Sociological Quarterly 23: 3-16.

Mortimer J T, Lorence J, and Kumka D S (1986) Work, Family, and Personality: Transition to Adulthood. Norwood, NJ: Ablex Publishing Corporation.

Moschis G P (1985) The Role of Family Communication in Consumer Socialization of Children and Adolescents. Journal of Consumer Research, 11: 898-913.

Moschis G P, Moore, R L (1979) Decision Making Among the Young: A Socialization Perspective. The Journal of Consumer Research, 6: 101-112.

Moschis G P, Moore, R L (1984) Anticipatory Consumer Socialization. Journal of the Academy of Marketing Science, 4: 109-123.

National Centre for Educational Statistics (2004) "College Persistence on the Rise?: Changes in 5-year Degree Completion and Postsecondary Persistence Rates between 1994 and 2000." Retrieved February 13, 2009, from http://nces.ed.gov/pubs2005/2005156.pdf

Orr A J (2003) Black-White Differences in Achievement: The Importance of Wealth. Sociology of Education 76: 281-304.

Pallas A M (2003) Educational Transitions, Trajectories, and Pathways. In Mortimer, JT, Shanahan, MJ eds. Handbook of the Life Course. Pp. 165-184. New York: Kluwer Academic/Plenum Publishers. 
Piotrkowski C S (1978) Work and the Family System: A Naturalistic Study of Working-Class and LowerMiddle Class Families. New York: Free Press.

Roberts, K (1968) The Entry into Employment: An Approach towards a General Theory. Sociological Review 16: 165-184.

Ryu S and J T Mortimer. (1996) The 'Occupational Linkage Hypothesis' applied to Occupational Value Formation in Adolescence. In Mortimer J T, Finch M D eds. Adolescents, Work, and Family: An Intergenerational Developmental Analysis. Pp. 167-190. Thousand Oaks: Sage Publications.

Schneider B, Stevenson, D (1999) The Ambitious Generation. America's Teenagers, Motivated but Directionless. Yale University Press.

Schoeni R, Ross K (2004) Material Assistance Received from Families during the Transition to Adulthood. In Settersten R A Jr., Furstenberg F, Jr., Rumbaut R eds. On the Frontier of Adulthood: Theory, Research, and Public Policy. Pp. 396-416. Chicago University of Chicago Press.

Sewell W, Hauser R (1975) Education, Occupation, and Earnings: Achievement in the Early Career. New York: Academic Press.

Shanahan M J (2000) Pathways to Adulthood in Changing Societies: Variability and Mechanisms in Life Course Perspective. Annual Review of Sociology 26: 667-692.

Shanahan M. J., Elder G H, Jr., and Miech R A. (1997) History and Agency in Men's Lives: Pathways to Achievement in Cohort Perspective. Sociology of Education 70: 54-67.

Shapiro T. M., Wolff E N eds. (2001) Assets for the Poor: The Benefits of Spreading Asset Ownership. New York: Russell Sage Foundation.

Smeeding T M, Phillips K R (2002) Cross-National Differences in Employment and Financial Independence. Annals of the American Academy of Political and Social Science 580: 103-133.

Staff J, Mortimer J T (2007) “Educational and Work Strategies from Adolescence to Early Adulthood: Consequences for Educational Attainment." Social Forces 85: 1169-1194.

Whittington L A, Peters E (1996) "Economic Incentives for Financial and Residential Independence." Demography 33: 82-97. 